\title{
1 Shear Loads Induce Cellular Damage in Tendon Fascicles
}

2

3 Jaclyn Kondratko-Mittnacht, ${ }^{\mathrm{a}, \mathrm{b}}$ Roderic Lakes, ${ }^{\mathrm{c}, \mathrm{d}}$ Ray Vanderby, Jr. ${ }^{\mathrm{a}, \mathrm{b}, \mathrm{c}, *}$

4

$5 \quad{ }^{a}$ Department of Biomedical Engineering, University of Wisconsin-Madison, Madison, WI, USA 53705

${ }^{\mathrm{b}}$ Department of Orthopedics and Rehabilitation, University of Wisconsin-Madison, Madison, WI, USA 53705

$7 \quad$ 'Materials Science Program, University of Wisconsin-Madison, Madison, WI, USA 53705

$8 \quad{ }^{d}$ Department of Engineering Physics, University of Wisconsin-Madison, Madison, WI, USA 53705

9

10 *Corresponding author: Ray Vanderby, Jr., Room 5059, 1111 Highland Ave., Madison, WI, USA, 53705, phone: 1-

11 608-263-9593, fax: 1-608-265-9144, e-mail: vanderby@ortho.wisc.edu

12

13 Word Count: 3479

14

(C) 2015. This manuscript version is made available under the Elsevier user license

http://www.elsevier.com/open-access/userlicense/1.0/ 


\section{Abstract}

Tendon is vital to musculoskeletal function, transferring loads from muscle to bone for joint motion and stability. It is an anisotropic, highly organized, fibrous structure containing primarily type I collagen in addition to tenocytes and other extracellular matrix components contributing to maintenance and function. Tendon is generally loaded via normal stress in a longitudinal direction. However, certain situations, including fiber breakage, enzymatic remodeling, or tendon pathology may introduce various degrees of other loading modalities, such as shear-lag at the fiber level, potentially affecting cellular response and subsequent function. Fascicles from rat tail tendon were dissected and placed in one of three paired groups: intact, single laceration, or double laceration. Each pair had a mechanically tested and control specimen. Single laceration fascicles contained one transverse laceration to mimic a partial tear. Double laceration fascicles had overlapping, longitudinally separated lacerations on opposite sides to cause intra-fascicular shear transfer to be the primary mechanism of loading. Elastic properties of the fascicle, e.g. peak load, steady state load, and stiffness, decreased from intact to single laceration to double laceration groups. Surprisingly, $45 \%$ of the intact strength was maintained when shear was the primary internal load transfer mechanism. Cellular viability decreased after mechanical testing in both laceration groups; cell death appeared primarily in a longitudinal plane where high shear load transfer occurred. This cell death extended far from the injury site and may further compromise an already damaged tendon via enzymatic factors and subsequent remodeling associated with cell necrosis.

\footnotetext{
Keywords: Tendon, Mechanics, Shear, Cellular Viability, Viscoelasticity
} 
Introduction

Tendon connects muscle to bone and functions to transfer muscle load for the movement and stabilization of joints. It consists primarily of the structural protein type I collagen but also contains tendon cells (tenocytes), proteoglycans, and elastin. Tendon structure is highly organized and hierarchical in nature, starting with the collagen molecule which combines to form collagen fibrils, fibers, fascicles, and finally the tendon (Screen, Bader, Lee, and Shelton, 2004). Collagen fibrils have been reported as the tendon's primary load-bearing structures (Szczesny and Elliott, 2014).

Tendon is principally loaded in the longitudinal direction, parallel to its fibers. Therefore, axial 44 loading is extensively investigated in vitro, with testing designed to apply a load as uniform as possible across the tendon's cross-section (Abrahams, 1967; Rigby, Hirai, Spikes, and Eyring, 1959). Whole tendon and smaller levels of its hierarchy are viscoelastic (Duenwald, Vanderby, and Lakes, 2009;

47 Kondratko, Duenwald-Kuehl, Lakes, and Vanderby, 2012; Screen, 2008; Woo, Johnson, and Smith, 1993), 48 nonlinear (Lake, Miller, Elliott, and Soslowsky, 2009; Lynch, Johannessen, Wu, Jawa, and Elliott, 2003), 49 and anisotropic in nature (Lynch et al., 2003) when tested in this orientation.

Whole tendon can stretch up to $4 \%-6 \%$ strain in vivo (Gardiner, Weiss, and Rosenberg, 2001; 51 Kongsgaard, Nielsen, Hegnsvad, Aagaard, and Magnusson, 2011; Lochner, Milne, Mills, and Groom, 52 1980). However, studies comparing strain at different levels of tendon hierarchy have shown that lower 53 hierarchical levels stretch to lower strains than higher levels. For instance, fascicles have been shown to 54 stretch to $55-90 \%$ of the whole tendon strain during loading, depending on the tendon type (Thorpe, 55 Udeze, Birch, Clegg, and Screen, 2012). Screen et al. have similarly shown that tendon fibers only 56 display $15 \%$ of the strain seen in the fascicle during testing (Screen et al., 2004), and Puxkankl et al. have 57 shown that fibrils only display $10-40 \%$ of the strain seen in whole tendon (Puxkandl et al., 2002). This 58 discrepancy in strain between hierarchical levels has been explained by sliding of fascicles, fibers, and 
fibrils relative to one another (Ahmadzadeh, Connizzo, Freedman, Soslowsky, and Shenoy, 2013;

60 Puxkandl et al., 2002; Screen, Bader, et al., 2004; Szczesny and Elliott, 2014; Thorpe et al., 2012). This

61 sliding could generate shear loading between tendon hierarchical components during normal,

62 physiological stretches.

With injury tendon strength and optimal function are compromised (Bishop, Cooney, and Wood, 1986; Child, Bryant, Clark, and Crossley, 2010; Dobyns, Cooney, and Wood, 1982; Duenwald-Kuehl, Kondratko, Lakes, and Vanderby, 2012; Duenwald-Kuehl, Lakes, and Vanderby Jr., 2012; Hariharan, Diao, Soejima, and Lotz, 1997; Kondratko et al., 2012; Mazzocca et al., 2008; McCarthy et al., 1995; Tan,

67 Wang, Tan, Xu, and Tang, 2003). Specifically, tendon laceration or tear decreases ultimate load (Bishop et al., 1986; Dobyns et al., 1982; Hariharan et al., 1997; Mazzocca et al., 2008; McCarthy et al., 1995; Tan et al., 2003), stiffness (Bey, Ramsey, and Soslowsky, 2002; Bishop et al., 1986; Kondratko et al., 2012; Mazzocca et al., 2008; McCarthy et al., 1995), and viscoelastic parameters (Kondratko et al., 2012) in vitro. Mechanical compromise due to laceration is disproportional to laceration area (Kondratko et al.,

72 2012), indicating that hierarchical levels of tendon do not behave as independent load bearing

73 structures as depicted in simplified structural models. Instead, levels of shear-lag and load transfer 74 above those seen during normal loading must occur between fibrils and fascicles, as suggested in other 75 studies (Ahmadzadeh et al., 2013; Kondratko-Mittnacht, Duenwald-Kuehl, Lakes, and Vanderby Jr., 76 2015; Pensalfini, Duenwald-Kuehl, Kondratko-Mittnacht, Lakes, and Vanderby Jr., 2014; Szczesny and 77 Elliott, 2014). Although some studies conclude that shear force transmission capability is negligible 78 between isolated tendon fascicles (Haraldsson et al., 2008; Purslow, 2009), Kondratko et al. report a 79 larger shear load transfer potential between fascicles when observing whole tendon behavior 80 (Kondratko-Mittnacht et al., 2015). Authors used transversely overlapping cuts (each $60 \%$ of the tendon 81 depth) such that no fascicles were contiguous grip-to-grip. In this configuration, tendons maintained $8220 \%$ of their intact strength and stiffness (Kondratko-Mittnacht et al., 2015). 
Beyond affecting mechanical function, abnormal levels of tendon loading mechanisms, such as shear,

84 as utilized by Kondratko-Mittnacht et al. in (Kondratko-Mittnacht et al., 2015) or in vivo by partial tears, tendinopathy, or local remodeling, would affect nearby cells. In response to altered mechanical load, tenocytes change tendon structure, composition, and mechanical properties by adjusting extracellular

87 matrix (ECM) protein expression (Banes et al., 1999; Chiquet, 1999; M. Kjær et al., 2009; Kjær, 2004).

Additionally, excess stretch or stress of tenocytes may cause apoptosis, necrosis, or plasma membrane disruption (Millar, Wei, Molloy, Bonar, and Murrell, 2009; Scott et al., 2005), potentially releasing inflammatory factors into the ECM (Hosaka, Teraoka, Yamamoto, Ueda, and Takehana, 2005; Lian et al., 2007; Yuan, Murrell, Wei, and Wang, 2002; Yuan, Wang, and Murrell, 2003). Therefore, an increased level of the shear internal loading mechanism would significantly modify cell signaling or viability and likely degrade mechanical behavior and function or cause tendinopathy over time.

There have been relatively few studies investigating shear behavior within tendon and its effect on cells, despite its importance. Shear is present within tendon as a primary loading mechanism to redistribute load near insertion sites during joint movement, during fiber breakage and remodeling due

97 to fatigue, and exaggerated under abnormal circumstances, such as around tendon partial tear, laceration, or tendinopathy. Shear load transfer is also an integral component of tendon lengthening procedures used to treat diabetic plantar forefoot ulceration (Mueller, Sinacore, Hastings, Strube, and Johnson, 2003), where multiple transections are created on alternating sides of the tendon (Hoke, 1931; Mueller et al., 2003; Salamon, Pinney, Bergeyk, and Hazelwood, 2006). Therefore, the purpose of this study is to investigate the mechanical and cellular response, in the form of tenocyte viability, to excess shear and axial loading (which includes physiologic levels of shear in the form of sliding between hierarchical components) within tendon fascicles. We hypothesize that cellular viability and mechanical properties will be adversely affected more by the excess shear loading mechanism than axial loading of the fascicles. 
Forty-eight (48) rat tail tendon fascicles from 10 2-3 month old male Wistar rats with a mass of about $300 \mathrm{~g}$ were used in this study. Fascicles were carefully dissected from tail tendons of rats that were

111 humanely euthanized immediately before fascicle removal, following a protocol approved by the 112 University of Wisconsin Institutional Animal Use and Care Committee. No more than 5 paired fascicles 113 of similar apparent diameters were removed from each rat to minimize cell death. The study had 3 114 paired groups ( $n=8$ pairs per group): 1) double laceration (obtained from 4 different rats), 2) single 115 laceration (obtained from 5 rats), and 3) intact fascicles (obtained from 6 rats), each with fascicles 116 assigned to a mechanically tested and not mechanically tested sub-group (Table 1). The group 117 assignments of fascicle pairs obtained from a single rat had some overlap between groups; however no 118 rats contained pairs from all groups (explaining the discrepancy between the total rats utilized for each 119 group). Laceration patterns for the double and single laceration pairs are shown in Figure 1. The double 120 lacerations were created to ensure shear load transfer, while the single laceration was created to more 121 clearly observe load transfer around a clinically relevant partial laceration/tear.

122 Lacerations were created in the transverse direction with a razor blade prior to loading samples in 123 the testing device. A razor blade was used to ensure cutting, not tearing of fibers to maintain fascicle 124 integrity and cellular viability in the surrounding area. Lacerations were created to a depth of about 50$12570 \%$ of the fascicle width in the locations shown in Figure 1 for each fascicle pair. The overlapping 126 lacerations ensured discontinuity of the majority of fibers between grips, thereby requiring shear to be 127 the primary mechanism required to resist axial loads. Measurements of the fascicle diameter or exact 128 laceration depth were not made because the goal was only to create a shear loading situation and to 129 prevent cell death. Hydration was maintained throughout the setup and testing by frequently spraying 
with physiologic buffered saline (PBS) as fascicles were unsubmerged during testing. Protocol

131 optimization verified that maintaining hydration with PBS at room temperature demonstrated minimal

132 cell death during the time required for dissection and testing.

\section{Mechanical Testing}

Fascicles in mechanical testing sub-groups were mounted into a servohydraulic mechanical testing 135 system (MTS) (Bionix 858; MTS, Minneapolis, Minnesota). Fascicles were gripped on both ends with two 136 soft tissue grips made of rough, interlocking plates. Care was taken to prevent undesired loading and 137 damage prior to beginning the testing protocol by ensuring no more than the weight of the fascicle itself 138 was placed on the specimen.

Prepared fascicles were placed into the MTS at an unloaded length of $45 \mathrm{~mm}$ (Fig. 1). Specimens were preloaded to $0.01 \mathrm{~N}$, and initial grip-to-grip length was measured using a digital caliper. Load was

141 measured with a 50lb load cell (Lebow Products Model 3397-50; Toronto, Ontario). Displacement was 142 controlled and measured with the MTS. All data were output to a PC with Labtech Notebook software 143 (Laboratory Technology Corporation; Fort Collins, Colorado).

Mechanical loading consisted of one sinusoidal, cyclic test (10 cycles at $0.5 \mathrm{~Hz}$ ) from 0 to $4 \%$ strain.

145 The strain level was selected to not cause mechanical damage but fall near the upper limit of physiologic 146 stretch in tendon (Gardiner et al., 2001; Kongsgaard et al., 2011; Lochner et al., 1980). Each control 147 specimen remained unloaded and hydrated during the time required for mechanical testing of its 148 paired, treated specimen.

Upon completion of mechanical testing, the LIVE/DEAD ${ }^{\circledR}$ Viability/Cytotoxicity (Molecular Probes ${ }^{\circledR}$; 151 Eugene, Oregon) assay was prepared. In this assay, ethidium homodimer-1 penetrates cells with compromised plasma membrane integrity to fluoresce the cell nuclei red (non-viable cells appear red in 
153 the images), while calcein-AM fluoresces cells with intracellular esterase activity green (viable cells

154 appear green). Prior to experimental testing, the assay was optimized for fascicle incubation to contain $1551 \mathrm{ml} \mathrm{PBS}, 5 \mu \mathrm{l}$ ethidium homodimer-1, and $1 \mu \mathrm{l}$ calcein-AM. The fascicles were placed in the media and 156 incubated at $37^{\circ} \mathrm{C}$ for $45 \mathrm{~min}$. Following incubation, fascicles were submerged in PBS to maintain 157 hydration until imaging.

$158 \quad$ Imaging

159 Imaging was completed on a Nikon A1RS high-speed confocal microscope equipped with green and 160 red excitation lasers. Images were recorded using NIS Elements viewer software $v 4.13$ (Nikon 161 Corporation, Tokyo, Japan). Fascicles were laid flat on a slide with a cover slip on top to prevent 162 dehydration. Imaging was through the 4x Plan Fluor/0.13 air immersion objective lens; all lacerations 163 were imaged, but locations near grips that may have been damaged due to handling during setup were 164 avoided. Scope settings remained the same for all fascicles to allow normalized comparisons.

\section{Mechanical Parameter Calculations}

Peak load, i.e. the maximum load recorded during testing, occurred slightly prior to the peak strain of 167 the initial cycle for all tests due to the viscoelastic nature of the fascicles. Additionally, a "steady state" 168 load was calculated as the average of the peak load of the final three cycles, representing the fascicle's 169 pseudo-elastic behavior. A viscoelastic parameter, load decay, was presented as the ratio of the 170 decrease in load from the peak of the initial cycle to the peak of the final cycle to the peak load 171 determined for that specimen. Stiffness was calculated as the slope of the linear region of the load172 displacement curve recorded during the rise of the final cycle. The linear region was determined visually 173 and was slightly variable between tests but was generally found to be between 1.5 and $3.7 \%$ strain. 174 Preconditioning was omitted by design in the protocol to minimize cellular death. The observed peak 
175 load and load decay may therefore be influenced by natural in vivo loading history and possibly 176 handling.

177 Image Analysis

178 Images of the fascicles were analyzed using ImageJ (NIH; Bethesda, Maryland). Using a constant 179 color threshold, the amount of red ('non-viable') and green ('viable') fluorescence were quantified as 180 the percent area of the whole image (calculated based on pixel numbers). To normalize the fascicles for 181 comparison, a ratio of the green percent area to the combined red and green percent areas was 182 calculated and defined as the cellular viability ratio.

183 Fascicle diameters were not measured from confocal images as the cover slip used to prevent 184 dehydration caused the fascicles to flatten, increasing the apparent diameter.

185 Statistics

186 For the mechanical analysis, a one-way ANOVA with a Fisher's least significant difference (LSD) post 187 hoc test was completed to compare groups for each mechanical parameter. In the LIVE/DEAD ${ }^{\circledR}$ analysis, 188 a one-way ANOVA with a Tukey post hoc test was completed to compare the cellular viability ratios 189 between sub-groups. Significance was defined as $p \leq 0.05$ for all statistics. All ANOVA calculations were 190 completed based on the number of fascicles per sub-group being compared.

\section{Results}

\section{Mechanical Analysis}

193 As anticipated, mechanical integrity for most parameters, i.e. peak load, steady state load, and 194 stiffness, decreased with increasing laceration number (intact to single laceration to double laceration). 195 For these parameters the ANOVA demonstrated statistical significance $(p<0.0001)$ between groups, and 196 the post hoc analysis showed a statistical difference between all three groups $(p<0.005)($ Fig. $2 a-c)$. The 
197 viscoelastic parameter, load decay ratio, demonstrated an increase in viscoelastic behavior with

198 laceration $(p<0.0001)$ (Fig. $2 d)$. The double laceration group had a significantly larger ratio than both 199 other groups $(p<0.0001)$, but the single laceration group was not different than the intact group $200 \quad(p=0.34)$.

202 The average cellular viability ratio was lower in mechanically tested sub-groups than their control, 203 untested counterparts for the single $(p=0.005)$ and double $(p<0.0001)$ laceration groups. The intact pair 204 did not demonstrate a difference between sub-groups $(p=0.998)$ (Fig. 3$)$. The double $(p<0.0001$ for all 205 comparisons) and single ( $\mathrm{p}<0.03$ for all comparisons) laceration mechanical tested sub-groups were 206 significantly different than all other sub-groups (excluding each other; $p=0.28$ ). No differences were 207 seen between not mechanically tested sub-groups ( $p>0.99$ for all comparisons).

208 Confocal images of the intact specimens showed no consistent areas of cell death due to mechanical 209 testing. Small areas of concentrated cell death were occasionally seen in both control and mechanically 210 tested specimens (Fig. 4). Conversely, both laceration groups demonstrated a pattern of significant, 211 localized cell death within the fascicle. As seen in Fig. 5 and 6, mechanical testing of fascicles in either 212 laceration group typically resulted in an axial plane of cell death. The plane of cell death in the single 213 laceration fascicles was normal to the tip of the laceration (Fig. 5) and either stretched along the length 214 of the fascicle $(n=5)$ or faded to look similar to the control, not mechanically stretched, fascicle as it 215 progressed away from the central laceration $(n=3)$. Similarly, the plane of cell death in the double 216 laceration fascicles connected the tip of one laceration to the tip of the opposite laceration (Fig. 6). 217 Notably, in one double laceration fascicle, two planes of cell death occurred, potentially due to a lack of 218 overlap in the lacerations.

\section{Discussion}


Various loading scenarios were created in this study to investigate differences in mechanical and

221 cellular response. In the single laceration group a $25 \%$ decrease in peak load compared to the intact

222 control was much smaller than the decrease seen by Kondratko et al. in whole tendons (Kondratko et

223 al., 2012), where a laceration of approximately 60\% reduced the peak load to 55\%. The double

224 laceration group tested here also demonstrated a smaller drop in peak load than seen by Kondratko-

225 Mittnacht et al. using a similar testing protocol in whole tendon (55\% compared to 80\%) (Kondratko-

226 Mittnacht et al., 2015). The variation in these laceration scenarios is likely a result of differing shear

227 transfer mechanisms at the two hierarchical levels. Previous studies have suggested that fiber sliding is

228 the dominant mechanism of elongation within tendon fascicles (Khodabakhshi et al., 2013; Li, Fessel,

229 Georgiadis, and Snedeker, 2013; Screen, Lee, Bader, and Shelton, 2004; Thorpe et al., 2013; Thorpe et

230 al., 2012) as well as the main mechanism for transferring load within tendon (Khodabakhshi et al., 2013).

231 Other studies have reported negligible lateral force transmission between fascicles (Haraldsson et al.,

232 2008; Purslow, 2009). The combination of these two observations may suggest that there is more shear

233 load transfer potential between fibers than fascicles. This suggestion is reinforced by the differences

234 seen in the shear transfer of the current study and the whole tendon study completed by Kondratko-

235 Mittnacht et al. (Kondratko-Mittnacht et al., 2015). The whole tendon study performed by Kondratko-

236 Mittnacht et al., exploiting inter-fascicular shear, caused a greater decrease in load than the current

237 experiment which tests the intra-fascicular shear (Kondratko-Mittnacht et al., 2015).

238 Viscoelastic response, quantified by the load decay ratio, increased upon introduction of the double

239 laceration. This was surprising because both single and double laceration at the whole tendon level had

240 a lesser viscoelastic response compared to the intact value (Kondratko et al., 2012; Kondratko-Mittnacht

241 et al., 2015). A comparison of the double laceration data collected in this study and whole tendon

242 tested by Kondratko-Mittnacht in (Kondratko-Mittnacht et al., 2015) is shown in Figure 7, demonstrating

243 more viscoelastic decay in lacerated fascicles than tendon. The differences between the hierarchical 
244 levels suggest that the inter-fibrillar interface has a greater impact on the viscoelastic response of whole 245 tendon than the inter-fascicular interface. This is supported by studies demonstrating that relaxation 246 primarily occurs due to sliding between fibers within tendon fascicles (Gupta, Seto, Krauss, Boesecke, 247 and Screen, 2010; Screen, 2008; Screen, Toorani, and Shelton, 2013).

Mechanical testing of the intact fascicle did not result in a decrease in the cellular viability ratio. This was inconsistent with the observation that low levels of strain cause cellular damage in whole ligament 250 (Provenzano, Heisey, Hayashi, Lakes, and Vanderby, 2002). However, the lack of cell death here may be 251 explained by the hierarchical level and the location of the imaged cells. While our cells were near the 252 fascicle surface (limited by the imaging technique), the fascicles were not located directly on the surface 253 of the tendon because the epitenon and endotenon were removed to allow better imaging of fascicular 254 cells. Provenzano et al. imaged cells on the surface of a whole ligament (Provenzano et al., 2002). Cells 255 within tendon fascicles may be more robust than those on the exterior of a ligament (Alberts et al., 256 2002).

257 Although mechanical testing of intact specimens did not decrease cellular viability, both single and 258 double laceration caused considerable cell necrosis after mechanical testing compared to control sub259 groups. Cell death in both laceration groups was localized to a longitudinal plane spanning the length of 260 the fascicle. Comparing the double laceration group, which allows primarily shear load transfer, to the 261 single laceration group, suggests that a partial laceration creates a plane of high shear load. This result 262 supports previous studies that conclude shear load transfer must be present around partial lacerations 263 to explain the disproportional drop in mechanical properties as a function of laceration depth 264 (Kondratko et al., 2012; Pensalfini et al., 2014).

265 Although cells can generally withstand small amounts of normal strains, axial or shear, during tendon 266 loading, cells are not well adapted for an excessive amount of these loading mechanisms. Therefore, 
cell death due to the exaggerated shear loading environment created here may be caused by high strain

268 on the cell plasma membrane resulting in its disruption, necrosis, or subsequent apoptosis (Miller,

269 Connizzo, Feeney, and Soslowsky, 2012; Provenzano et al., 2002; Scott et al., 2005). Upon cell death,

270 factors stored in the cytosol may be released causing inflammation (Hetts, 1998; McNeil, 1993; Wyllie,

271 Kerr, and Currie, 1980), potentially affecting remodeling and repair of the tissue. However, early

272 mobilization of partially lacerated tendons has been reported to be beneficial to repair (Gelberman,

273 Woo, Lothringer, Akeson, and Amiel, 1982; Tanaka, Manske, Pruitt, and Larson, 1995).

This study provides insight into the mechanical and cellular response of tendon fascicles to excess

275 levels of shear loading; however, there are limitations to discuss. All protocols were performed on

276 fascicles from rat tail tendon due to the ease of fascicle removal and the magnitude of literature for

277 comparison; similar information should be studied on other tendons. While the double laceration group

278 was included to investigate shear load transfer capability and cellular response between fibers, without

279 measuring the fiber alignment within the fascicle, the fascicle diameter, or depth of lacerations, the

280 authors cannot be confident that axial loading of some remaining intact fibers did not provide a portion

281 of the strength of those specimens. It has been reported that fibrils within equine energy storing and

282 positional tendon fascicles exhibit a helical orientation; however, the positional tendon fascicle, which is

283 more similar to the rat tail tendon, exhibits less of a helical pitch angle (Thorpe et al., 2013). This helical

284 orientation suggests that a portion of the fibrils or fibers may bypass the overlapping lacerations.

285 Although, it is clear through the cellular viability portion of this study, that an abnormal loading

286 mechanism (excess shear) is causing significant cell death in that experimental group. During

287 mechanical testing and setup, evaporation of PBS from the surface of the fascicle occurred quickly due

288 to the fascicle size, affecting cellular viability in some instances and resulting in small drift during

289 preload. As a result, preload was not held long to allow for complete stabilization. However, due to the

290 low preload compared to values seen during testing and the short testing time, the small drift seen 
291 while preloading was unlikely to affect the overall mechanical results. Another limitation, that the 292 control, untested specimens were not loaded into the mechanical testing system, was incorporated into 293 the protocol to minimize handling and potential dehydration but this may have caused differences 294 between the groups. Because no difference in cellular viability was seen between intact mechanically 295 loaded and their not loaded control specimens, it is believed that untested specimens provided a 296 reliable control. Finally, despite care taken to prevent unnecessary handling of the fascicles, some 297 localized areas of cell death were seen in the LIVE/DEAD analysis. Since these areas were random and 298 occurred in all groups, they were assumed to not affect results in this manuscript. If a fascicle had large 299 areas of cell death deemed due to dehydration or handling, it was removed from the study.

Despite these experimental limitations, this study provides insight into the shear loading mechanism 301 in tendon. Shear occurs as a primary loading mechanism during normal loading situations (e.g. sliding 302 between hierarchical levels, load transfer around fiber breakage or enzymatic remodeling, or during 303 insertion site rotation during joint movement). It is also an integral aspect of loading during tendon 304 injury, such as partial tear, laceration, or tendinopathy, where it is present at an exaggerated level. 305 Shear is the main loading mechanism after tendon lengthening procedures used to treat diabetic plantar 306 forefoot ulceration (Mueller et al., 2003). Experimentally, the double laceration group provided 307 mechanical and cellular insight into these lengthening procedures and a baseline for the behaviors seen 308 in the single laceration case which more closely mimics partial tear injuries. Although surgical repair of 309 injured tendon is primarily based upon strength of the damaged tendon (Bishop et al., 1986; Dobyns et 310 al., 1982; Hariharan et al., 1997; Manning, Spiguel, and Mass, 2010; McCarthy et al., 1995; Tan et al., 311 2003), this study suggests that cellular response should not be overlooked, and needs further 312 investigation.

\section{Conclusions}


This study describes mechanical and cellular response to a laceration model focusing on shear

315 loading within rat tail tendon fascicles. With the exception of the viscoelastic parameter, which

316 increased after laceration, mechanical properties decreased with increasing laceration number (single to

317 double laceration). Surprisingly, even with overlapping lacerations in the fascicles, eliminating the

318 majority of full length intact fibers, the fascicle retained about $45 \%$ of its intact load capacity when

319 tested at the same grip-to-grip strain level, suggesting that the ability of whole tendon to bear shear

320 load (Kondratko-Mittnacht et al., 2015) is likely limited by mechanisms at other hierarchical levels.

321 Despite the surprising loading capacity maintained during exaggerated shear loading, cellular necrosis

322 increased in both laceration groups, demonstrating significant necrosis in a longitudinal plane,

323 corresponding to the plane of greatest shear. Interestingly, cell damage due to a localized injury, such

324 as the laceration created here, can span a significant distance in both directions from the site of injury.

325

326

327 Acknowledgements

328 Support by the National Science Foundation (Award CMMI-1432937) and National Institute of 329 Arthritis and Musculoskeletal and Skin Disease of the National Institutes of Health (Award EB008548) are 330 gratefully acknowledged. The content is solely the responsibility of the authors and does not necessarily 331 represent the official views of the National Institutes of Health. The authors also thank Ron McCabe for 332 his technical assistance.

\section{References}

335 Abrahams, M., 1967. Mechanical behaviour of tendon In vitro. Medical and Biological Engineering, 5(5), 433-443. doi:10.1007/BF02479137 
Ahmadzadeh, H., Connizzo, B. K., Freedman, B. R., Soslowsky, L. J., \& Shenoy, V. B., 2013. Determining the contribution of glycosaminoglycans to tendon mechanical properties with a modified shearlag model. Journal of Biomechanics, 46(14), 2497-2503. doi:10.1016/j.jbiomech.2013.07.008

Alberts, B., Johnson, A., Lewis, J., Raff, M., Roberts, K., \& Walter, P., 2002. Molecular Biology of the Cell (4th ed.). Garland Science.

Banes, A. J., Horesovsky, G., Larson, C., Tsuzaki, M., Judex, S., Archambault, J., ... Miller, L., 1999. Mechanical load stimulates expression of novel genesin vivoandin vitroin avian flexor tendon cells. Osteoarthritis and Cartilage, 7(1), 141-153. doi:10.1053/joca.1998.0169

Bey, M. J., Ramsey, M. L., \& Soslowsky, L. J., 2002. Intratendinous strain fields of the supraspinatus tendon: Effect of a surgically created articular-surface rotator cuff tear. Journal of Shoulder and Elbow Surgery, 11(6), 562-569.

Bishop, A. T., Cooney, W. P., 3rd, \& Wood, M. B., 1986. Treatment of partial flexor tendon lacerations: the effect of tenorrhaphy and early protected mobilization. The Journal of Trauma, 26(4), 301312.

Child, S., Bryant, A. L., Clark, R. A., \& Crossley, K. M., 2010. Mechanical Properties of the Achilles Tendon Aponeurosis Are Altered in Athletes With Achilles Tendinopathy. The American Journal of Sports Medicine, 38(9), 1885-1893. doi:10.1177/0363546510366234

Chiquet, M., 1999. Regulation of extracellular matrix gene expression by mechanical stress. Matrix Biology, 18(5), 417-426. doi:10.1016/S0945-053X(99)00039-6

Dobyns, R. C., Cooney, W. C., \& Wood, M. B., 1982. Effect of partial lacerations on canine flexor tendons. Minnesota Medicine, 65(1), 27-32.

Duenwald-Kuehl, S., Kondratko, J., Lakes, R., \& Vanderby, R., 2012. Damage Mechanics of Porcine Flexor Tendon: Mechanical Evaluation and Modeling. Annals of Biomedical Engineering, 40(8), 16921707. doi:10.1007/s10439-012-0538-z 
Duenwald-Kuehl, S., Lakes, R., \& Vanderby Jr., R., 2012. Strain-induced damage reduces echo intensity changes in tendon during loading. Journal of Biomechanics, 45(9), 1607-1611. doi:10.1016/j.jbiomech.2012.04.004

Duenwald, S. E., Vanderby, R., \& Lakes, R. S., 2009. Viscoelastic Relaxation and Recovery of Tendon. Annals of Biomedical Engineering, 37(6), 1131-1140.

Gardiner, J. C., Weiss, J. A., \& Rosenberg, T. D., 2001. Strain in the human medial collateral ligament during valgus loading of the knee. Clinical Orthopaedics and Related Research, 391, 266-274.

Gelberman, R. H., Woo, S. L.-Y., Lothringer, K., Akeson, W. H., \& Amiel, D., 1982. Effects of early intermittent passive mobilization on healing canine flexor tendons. The Journal of Hand Surgery, 7(2), 170-175. doi:10.1016/S0363-5023(82)80083-X

Gupta, H. S., Seto, J., Krauss, S., Boesecke, P., \& Screen, H. R. C., 2010. In situ multi-level analysis of viscoelastic deformation mechanisms in tendon collagen. Journal of Structural Biology, 169(2), 183-191. doi:10.1016/j.jsb.2009.10.002

Haraldsson, B. T., Aagaard, P., Qvortrup, K., Bojsen-Moller, J., Krogsgaard, M., Koskinen, S., ... Magnusson, S. P., 2008. Lateral force transmission between human tendon fascicles. Matrix Biology, 27(2), 86-95. doi:10.1016/j.matbio.2007.09.001

Hariharan, J. S., Diao, E., Soejima, O., \& Lotz, J. C., 1997. Partial lacerations of human digital flexor tendons: a biomechanical analysis. The Journal of Hand Surgery, 22(6), 1011-1015. doi:10.1016/S0363-5023(97)80040-8

Hetts SW., 1998. To die or not to die: An overview of apoptosis and its role in disease. The Journal of the American Medical Association, 279(4), 300-307. doi:10.1001/jama.279.4.300

Hoke, M., 1931. An Operation for the Correction of Extremely Relaxed Flat Feet. The Journal of Bone \& Joint Surgery, 13(4), 773-783. 
Hosaka, Y., Teraoka, H., Yamamoto, E., Ueda, H., \& Takehana, K., 2005. Mechanism of Cell Death in Inflamed Superficial Digital Flexor Tendon in the Horse. Journal of Comparative Pathology, 132(1), 51-58. doi:10.1016/j.jcpa.2004.06.006

Khodabakhshi, G., Walker, D., Scutt, A., Way, L., Cowie, R. M., \& Hose, D. R., 2013. Measuring threedimensional strain distribution in tendon. Journal of Microscopy, 249(3), 195-205. doi:10.1111/jmi.12009

Kjær, M., 2004. Role of Extracellular Matrix in Adaptation of Tendon and Skeletal Muscle to Mechanical Loading. Physiological Reviews, 84(2), 649-698. doi:10.1152/physrev.00031.2003

Kjær, M., Langberg, H., Heinemeier, K., Bayer, M. L., Hansen, M., Holm, L., ... Magnusson, S. P., 2009. From mechanical loading to collagen synthesis, structural changes and function in human tendon. Scandinavian Journal of Medicine \& Science in Sports, 19(4), 500-510. doi:10.1111/j.1600-0838.2009.00986.x

Kondratko, J., Duenwald-Kuehl, S., Lakes, R., \& Vanderby, R., 2012. Mechanical Compromise of Partially Lacerated Flexor Tendons. Journal of Biomechanical Engineering, 135(1), 011001-1-011001-8. doi:10.1115/1.4023092

Kondratko-Mittnacht, J., Duenwald-Kuehl, S., Lakes, R., \& Vanderby Jr., R., 2015. Shear load transfer in high and low stress tendons. Journal of the Mechanical Behavior of Biomedical Materials, 45, 109-120. doi:10.1016/j.jmbbm.2015.01.021

Kongsgaard, M., Nielsen, C. H., Hegnsvad, S., Aagaard, P., \& Magnusson, S. P., 2011. Mechanical properties of the human Achilles tendon, in vivo. Clinical Biomechanics, 26(7), 772-777. doi:10.1016/j.clinbiomech.2011.02.011

Lake, S. P., Miller, K. S., Elliott, D. M., \& Soslowsky, L. J., 2009. Effect of fiber distribution and realignment on the nonlinear and inhomogeneous mechanical properties of human supraspinatus tendon 
under longitudinal tensile loading. Journal of Orthopaedic Research, 27(12), 1596-1602. doi:10.1002/jor.20938

Lian, Ø., Scott, A., Engebretsen, L., Bahr, R., Duronio, V., \& Khan, K., 2007. Excessive Apoptosis in Patellar Tendinopathy in Athletes. The American Journal of Sports Medicine, 35(4), 605-611.

412 Li, Y., Fessel, G., Georgiadis, M., \& Snedeker, J. G., 2013. Advanced glycation end-products diminish doi:10.1177/0363546506295702 tendon collagen fiber sliding. Matrix Biology, 32(3-4), 169-177. doi:10.1016/j.matbio.2013.01.003

Lochner, F. K., Milne, D. W., Mills, E. J., \& Groom, J. J., 1980. In vivo and in vitro measurement of tendon strain in the horse. American Journal of Veterinary Research, 41(12), 1929-1937.

Lynch, H. A., Johannessen, W., Wu, J. P., Jawa, A., \& Elliott, D. M., 2003. Effect of Fiber Orientation and Strain Rate on the Nonlinear Uniaxial Tensile Material Properties of Tendon. Journal of Biomechanical Engineering, 125(5), 726-731. doi:10.1115/1.1614819

Manning, D. W., Spiguel, A. R., \& Mass, D. P., 2010. Biomechanical analysis of partial flexor tendon lacerations in zone II of human cadavers. The Journal of Hand Surgery, 35(1), 11-18. doi:10.1016/j.jhsa.2009.10.015

Mazzocca, A. D., Rincon, L. M., O’Connor, R. W., Obopilwe, E., Andersen, M., Geaney, L., \& Arciero, R. A., 2008. Intra-articular Partial-Thickness Rotator Cuff Tears. The American Journal of Sports Medicine, 36(1), $110-116$. doi:10.1177/0363546507307502

McCarthy, D. M., Tramaglini, D. M., Chan, S. S., Schmidt, C. C., Sotereanos, D. G., \& Herndon, J. H., 1995. Effect of partial laceration on the structural properties of the canine FDP tendon: an in vitro study. The Journal of Hand Surgery, 20(5), 795-800. doi:10.1016/S0363-5023(05)80434-4

McNeil, P. L., 1993. Cellular and molecular adaptations to injurious mechanical stress. Trends in Cell Biology, 3(9), 302-307. doi:10.1016/0962-8924(93)90012-P 
Millar, N. L., Wei, A. Q., Molloy, T. J., Bonar, F., \& Murrell, G. a. C., 2009. Cytokines and apoptosis in supraspinatus tendinopathy. Journal of Bone \& Joint Surgery, British Volume, 91-B(3), 417-424. doi:10.1302/0301-620X.91B3.21652

Miller, K. S., Connizzo, B. K., Feeney, E., \& Soslowsky, L. J., 2012. Characterizing local collagen fiber realignment and crimp behavior throughout mechanical testing in a mature mouse supraspinatus tendon model. Journal of Biomechanics, 45(12), 2061-2065. doi:10.1016/j.jbiomech.2012.06.006

Mueller, M. J., Sinacore, D. R., Hastings, M. K., Strube, M. J., \& Johnson, J. E., 2003. Effect of Achilles Tendon Lengthening on Neuropathic Plantar Ulcers: A Randomized Clinical Trial. The Journal of Bone \& Joint Surgery, 85(8), 1436-1445.

Pensalfini, M., Duenwald-Kuehl, S. E., Kondratko-Mittnacht, J. R., Lakes, R., \& Vanderby Jr., R., 2014. Evaluation of Global Load Sharing and Shear-lag Models to Describe Mechanical Behavior in Partially Lacerated Tendons. Journal of Biomechanical Engineering, 136(9), 091106. doi:10.1115/1.4027714

Provenzano, P. P., Heisey, D., Hayashi, K., Lakes, R., \& Vanderby, R., 2002. Subfailure damage in ligament: a structural and cellular evaluation. Journal of Applied Physiology, 92(1), 362-371.

Purslow, P. P., 2009. The shear modulus of connections between tendon fascicles. In Science and Technology for Humanity (TIC-STH), 2009 IEEE Toronto International Conference (pp. 134 -136). doi:10.1109/TIC-STH.2009.5444520

Puxkandl, R., Zizak, I., Paris, O., Keckes, J., Tesch, W., Bernstorff, S., ... Fratzl, P., 2002. Viscoelastic properties of collagen: synchrotron radiation investigations and structural model. Philosophical Transactions of the Royal Society of London B: Biological Sciences, 357(1418), 191-197. doi:10.1098/rstb.2001.1033 
Rigby, B. J., Hirai, N., Spikes, J. D., \& Eyring, H., 1959. The Mechanical Properties of Rat Tail Tendon. The Journal of General Physiology, 43(2), 265 -283. doi:10.1085/jgp.43.2.265

Salamon, M. L., Pinney, S. J., Bergeyk, A. V., \& Hazelwood, S., 2006. Surgical Anatomy and Accuracy of Percutaneous Achilles Tendon Lengthening. Foot \& Ankle International, 27(6), 411-413. doi:10.1177/107110070602700604

Scott, A., Khan, K. M., Heer, J., Cook, J. L., Lian, O., \& Duronio, V., 2005. High strain mechanical loading rapidly induces tendon apoptosis: an ex vivo rat tibialis anterior model. British Journal of Sports Medicine, 39(5), e25-e25. doi:10.1136/bjsm.2004.015164

Screen, H. R. C., 2008. Investigating load relaxation mechanics in tendon. Journal of the Mechanical Behavior of Biomedical Materials, 1(1), 51-58. doi:10.1016/j.jmbbm.2007.03.002

Screen, H. R. C., Bader, D. L., Lee, D. A., \& Shelton, J. C., 2004. Local Strain Measurement within Tendon. Strain, 40(4), 157-163. doi:10.1111/j.1475-1305.2004.00164.x

Screen, H. R. C., Lee, D. A., Bader, D. L., \& Shelton, J. C., 2004. An investigation into the effects of the hierarchical structure of tendon fascicles on micromechanical properties. Proceedings of the Institution of Mechanical Engineers, Part H: Journal of Engineering in Medicine, 218(2), 109-119. doi:10.1243/095441104322984004

Screen, H. R. C., Toorani, S., \& Shelton, J. C., 2013. Microstructural stress relaxation mechanics in functionally different tendons. Medical Engineering \& Physics, 35(1), 96-102. doi:10.1016/j.medengphy.2012.04.004

Szczesny, S. E., \& Elliott, D. M., 2014. Interfibrillar shear stress is the loading mechanism of collagen fibrils in tendon. Acta Biomaterialia, 10(6), 2582-2590. doi:10.1016/j.actbio.2014.01.032

Tanaka, H., Manske, P. R., Pruitt, D. L., \& Larson, B. J., 1995. Effect of cyclic tension on lacerated flexor tendons in vitro. The Journal of Hand Surgery, 20(3), 467-473. doi:10.1016/\$03635023(05)80109-1 
Tan, J., Wang, B., Tan, B., Xu, Y., \& Tang, J. B., 2003. Changes in Tendon Strength After Partial Cut and Effects of Running Peripheral Sutures. Journal of Hand Surgery (British and European Volume), 28(5), 478-482. doi:10.1016/S0266-7681(03)00168-2

Thorpe, C. T., Klemt, C., Riley, G. P., Birch, H. L., Clegg, P. D., \& Screen, H. R. C., 2013. Helical substructures in energy-storing tendons provide a possible mechanism for efficient energy storage and return. Acta Biomaterialia, 9(8), 7948-7956. doi:10.1016/j.actbio.2013.05.004

Thorpe, C., Udeze, C. P., Birch, H. L., Clegg, P. D., \& Screen, H. R. C., 2012. Specialization of tendon mechanical properties results from interfascicular differences. Journal of The Royal Society Interface, 3108-3117. doi:10.1098/rsif.2012.0362

Woo, S. L., Johnson, G. A., \& Smith, B. A., 1993. Mathematical modeling of ligaments and tendons. Journal of Biomechanical Engineering, 115(4B), 468-473.

Wyllie, A. H., Kerr, J. F. R., \& Currie, A. R., 1980. Cell Death: The Significance of Apoptosis. In J. F. D. and K. W. J. G.H. Bourne (Ed.), International Review of Cytology (Vol. 68, pp. 251-306). Academic Press. Retrieved from http://www.sciencedirect.com/science/article/pii/S0074769608623128

Yuan, J., Murrell, G. A. C., Wei, A.-Q., \& Wang, M.-X., 2002. Apoptosis in rotator cuff tendonopathy. Journal of Orthopaedic Research, 20(6), 1372-1379. doi:10.1016/S0736-0266(02)00075-X

Yuan, J., Wang, M.-X., \& Murrell, G. A. C., 2003. Cell death and tendinopathy. Clinics in Sports Medicine, 22(4), 693-701. 


\section{Table/Figure Legends}

Table 1. Description of experimental pairs used in the study.

Figure 1. Specimen preparation and mechanical testing setup. Pair 1 (double laceration) was prepared with 2 overlapping lacerations on opposite sides of the fascicle, one specimen was mechanically loaded, one was not. Pair 2 (single laceration) was prepared with a single, mid-substance, transverse laceration, one specimen was loaded, one was not. Both ends of the fascicles were gripped in soft-tissue grips with rough, interlocking plates on both sides.

Figure 2. Mechanical response of experimental groups (intact, single laceration, and double laceration). The addition of a laceration decreased the mechanical properties in peak load (a), steady state load (b), and stiffness (c). Load decay ratio demonstrated larger value in the double laceration group compared to the other two groups (d). An asterisk $(*)$ indicates significance $(p \leq 0.05)$.

Figure 3. Cellular response in each experimental sub-group. Average cellular viability ratio values resulted in differences between the single and double laceration mechanically tested sub-groups and all other sub-groups, excluding each other (not all differences shown on the graph). An asterisk $(*)$ indicates significance $(p \leq 0.05)$.

Figure 4. Confocal images of a representative intact pair. (a) Shows the control, not tested specimen and (b) shows the intact, mechanically tested specimen.

Figure 5. Confocal images of a representative single laceration pair. (a) Shows the control, not tested specimen and (b) shows the lacerated, mechanically tested specimen. Horizontal dark band corresponds to region of non-viable cells. 
Figure 6. Confocal images of a representative double laceration pair. (a) Shows the control, not tested specimen and (b) shows the lacerated, mechanically tested specimen. Horizontal dark band corresponds to region of non-viable cells.

Figure 7. Load decay ratio, normalized to the average intact value, for intact rat tail tendons and fascicles and those tested after introduction of overlapping lacerations. The lacerated fascicles demonstrated an increase in load decay ratio compared to the intact fascicle, while the lacerated tendon had a smaller load decay ratio than the intact tendon (though not significant; $p=0.22$ ). Data for whole tendon were measured by Kondratko-Mittnacht as a part of (Kondratko-Mittnacht et al., 2015). An asterisk $(*)$ indicates significance $(p \leq 0.05)$. 
Pair 1

[Double Laceration]

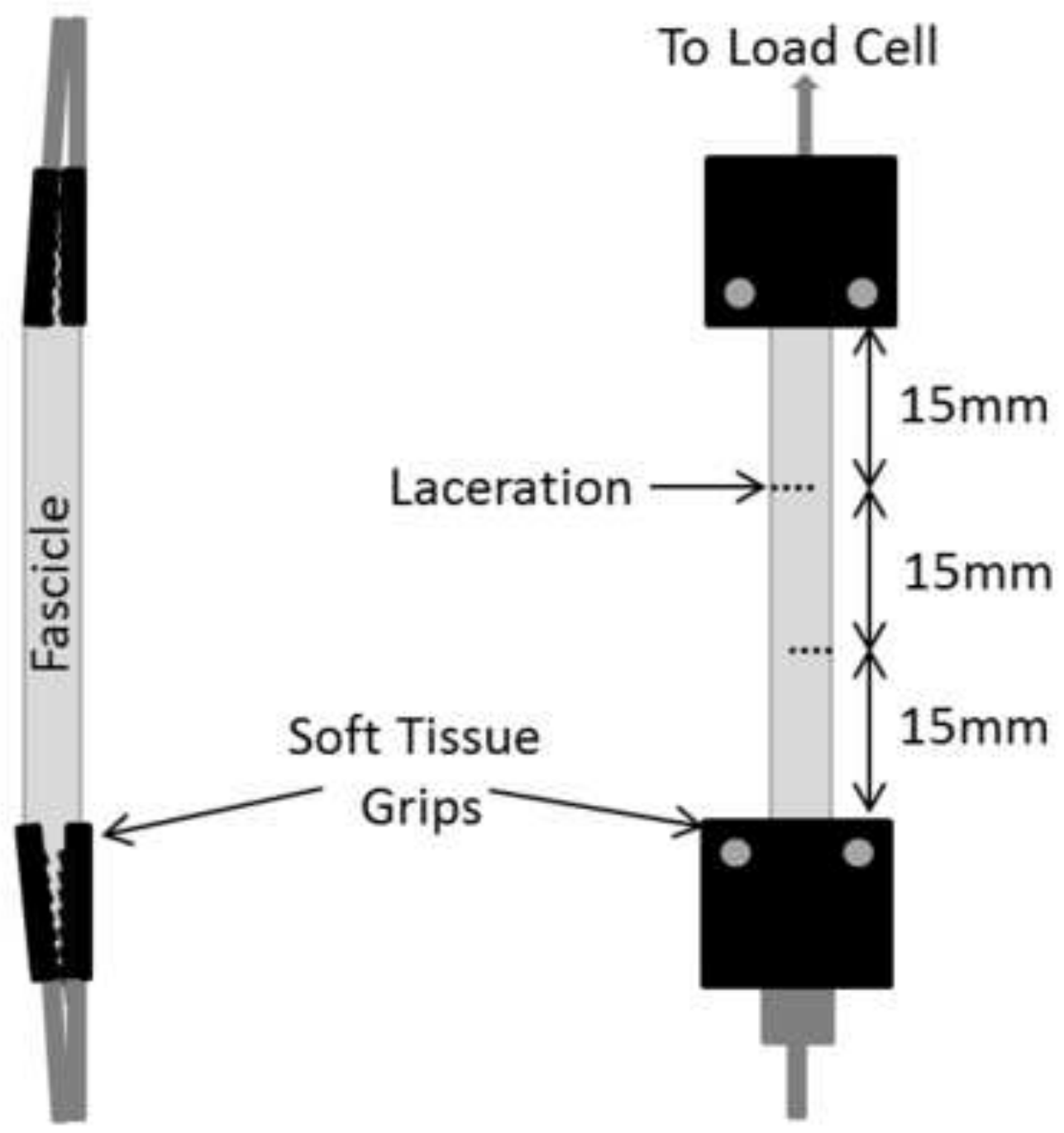

Pair 2

[Single Laceration]

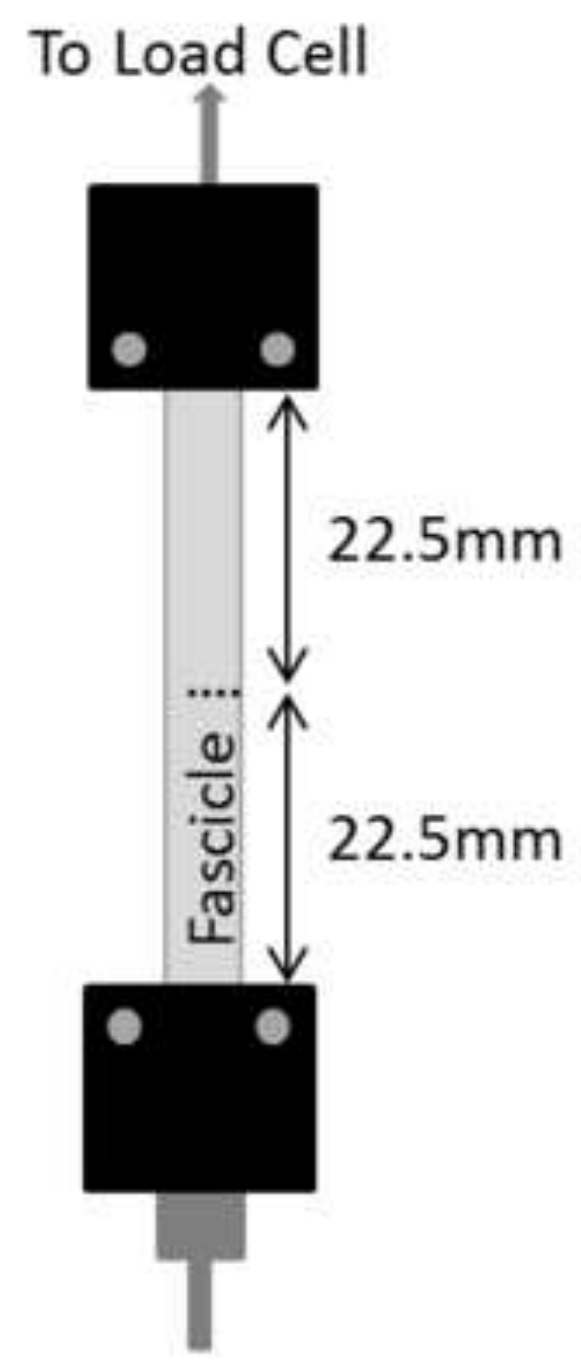




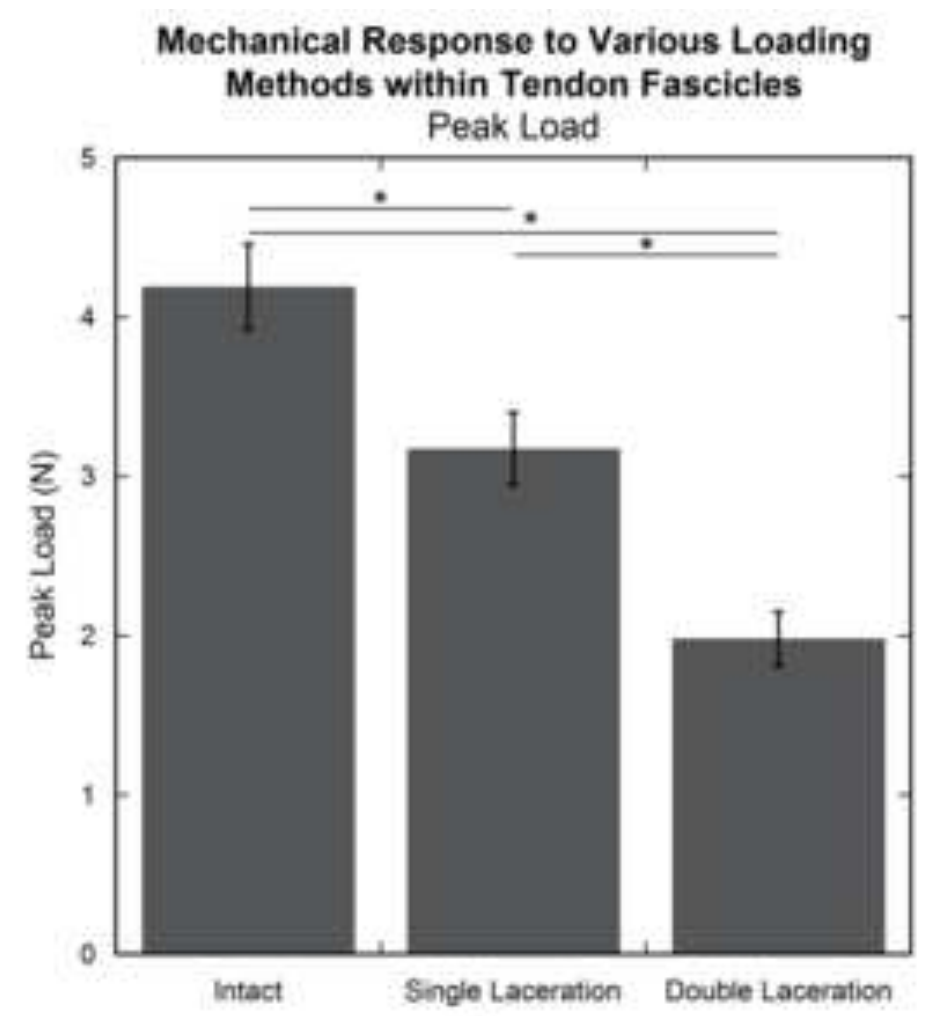

(a)

Mechanical Response to Various Loading

Methods within Tendon Fascicles

Stiffness

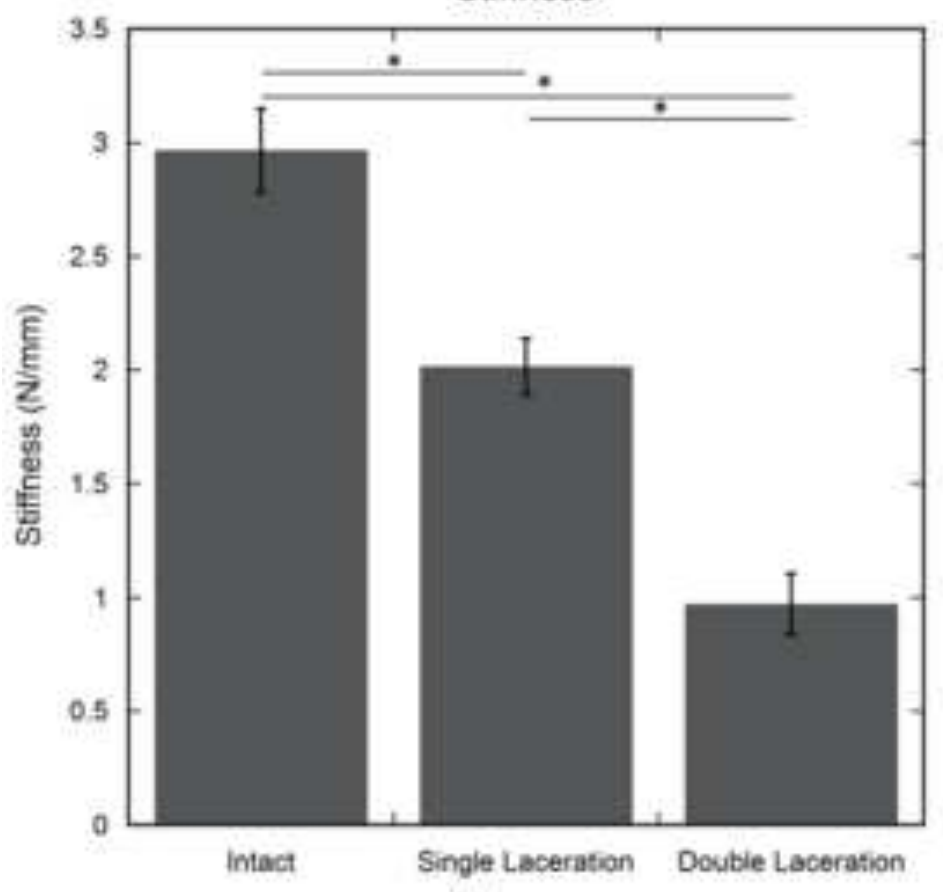

(c)
Mechanical Response to Various Loading Methods within Tendon Fascicles Steady State Load

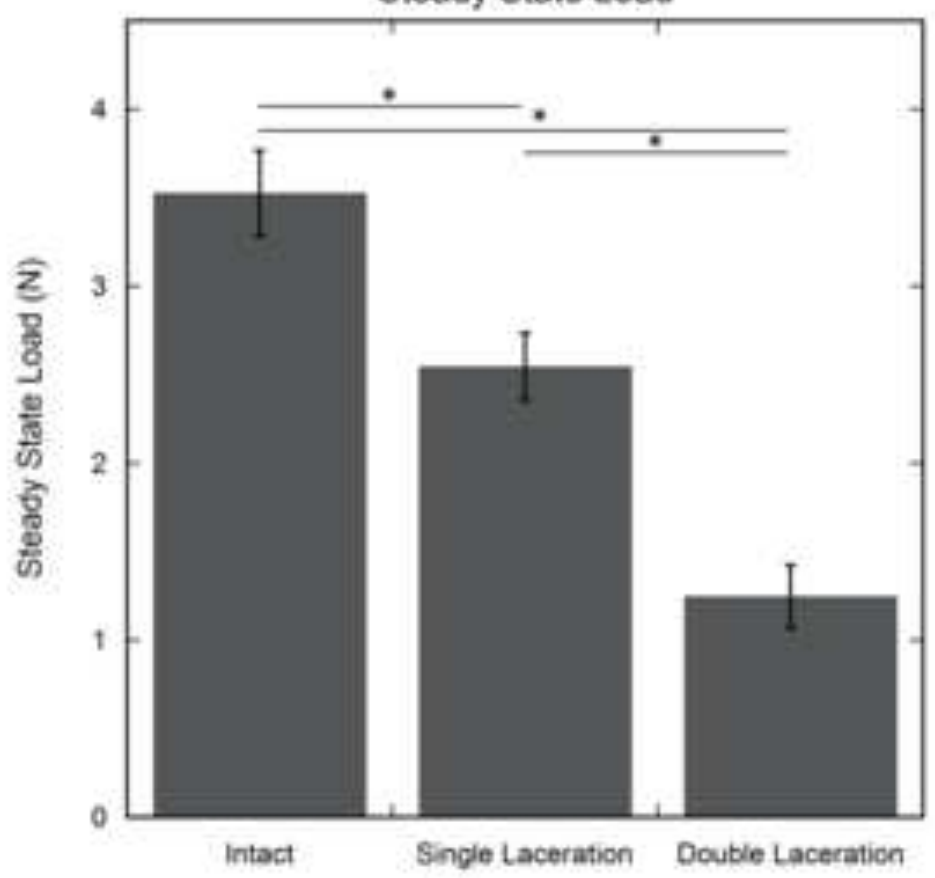

(b)

Mechanical Response to Various Loading Methods within Tendon Fascicles Load Decay/Peak Load

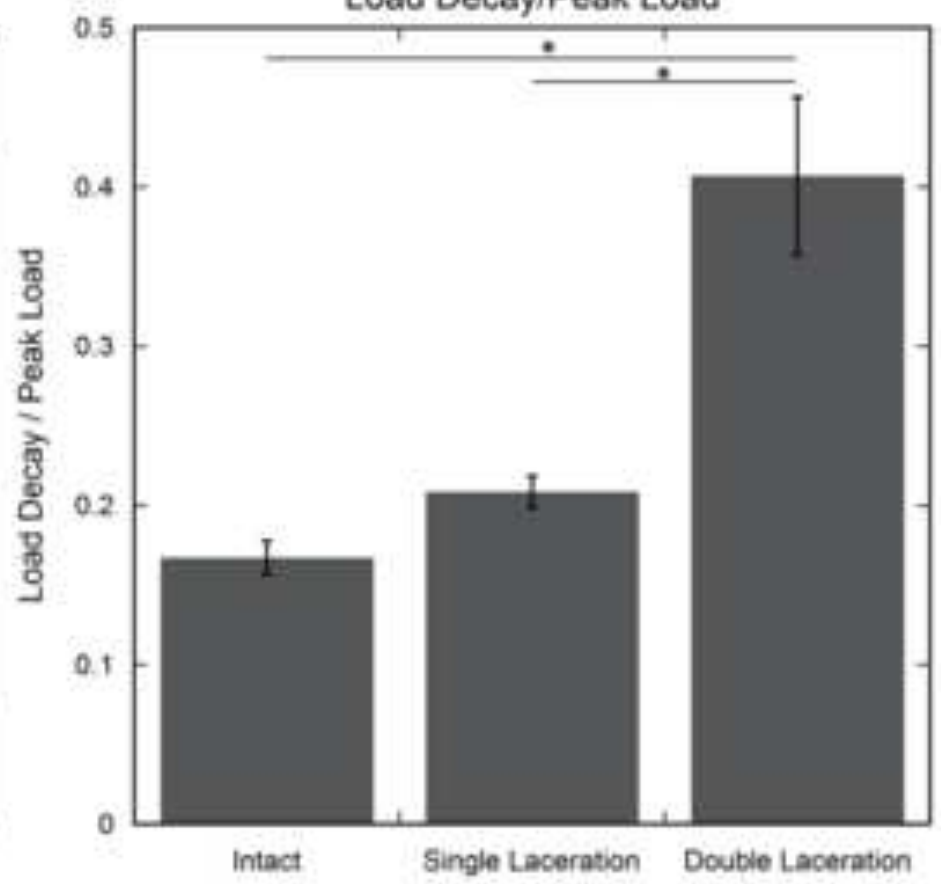

(d) 


\section{Cellular Response to Various Loading Methods within Tendon Fascicles}

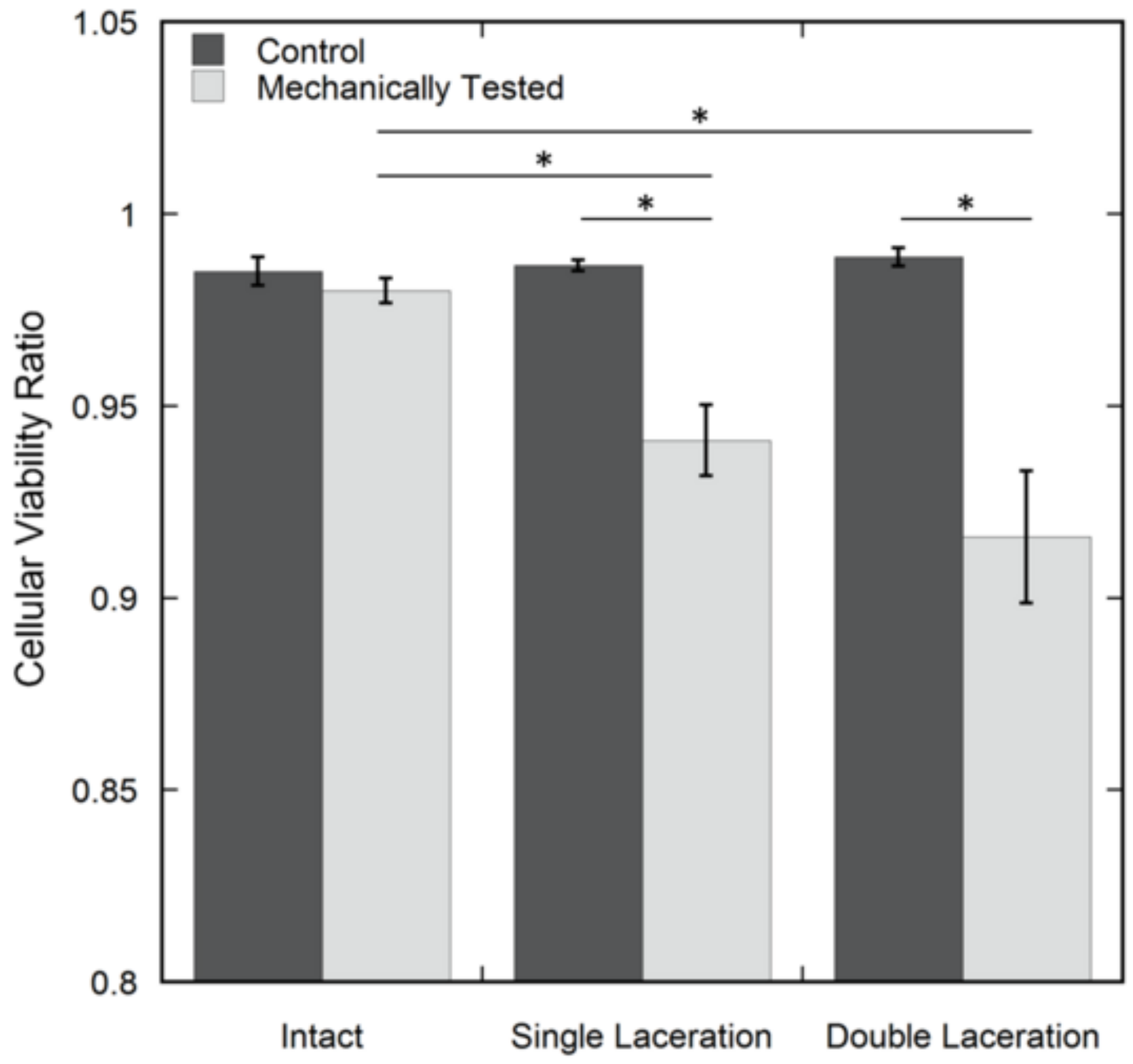




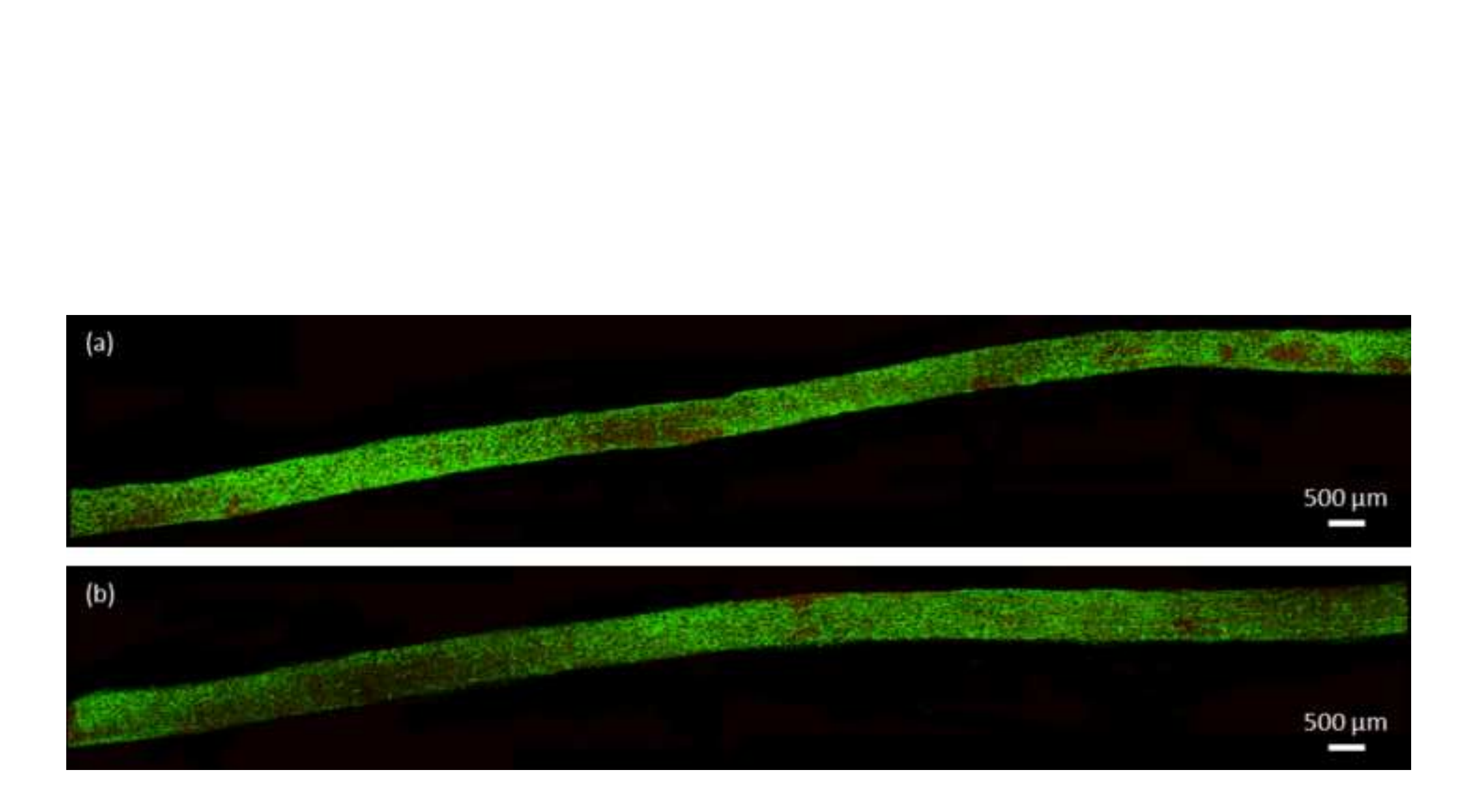




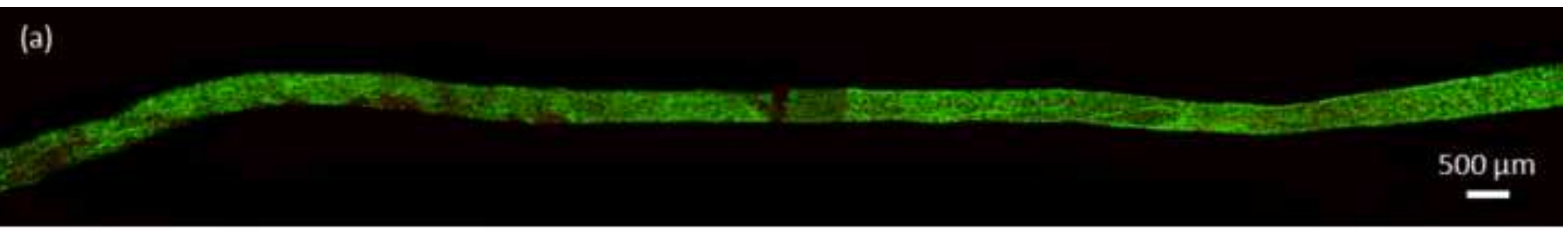

(b)

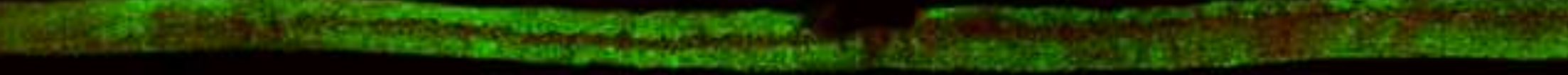

(1) 

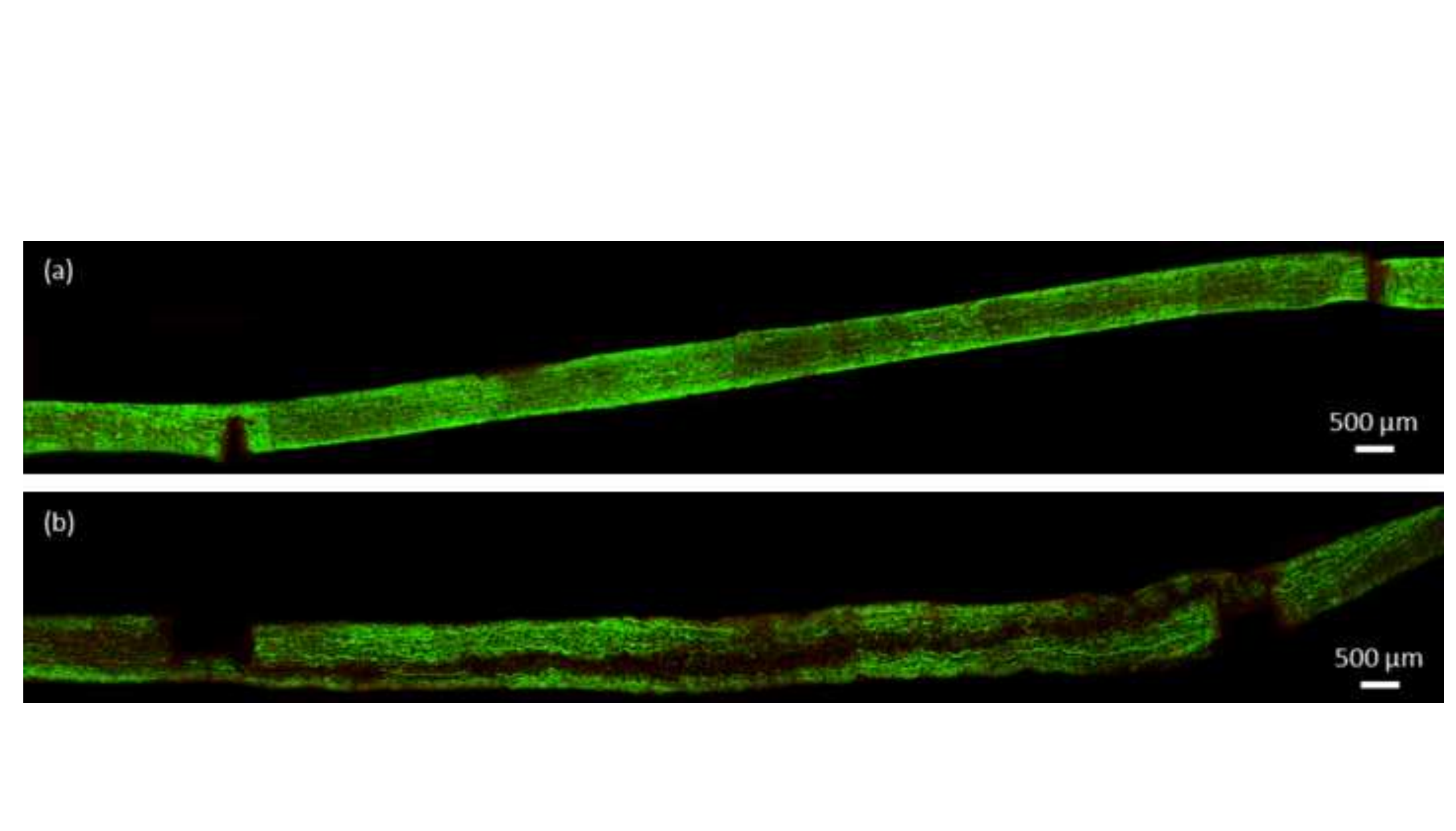

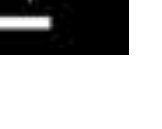

6

\section{.}

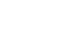

(-

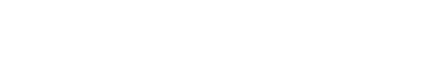

(2.
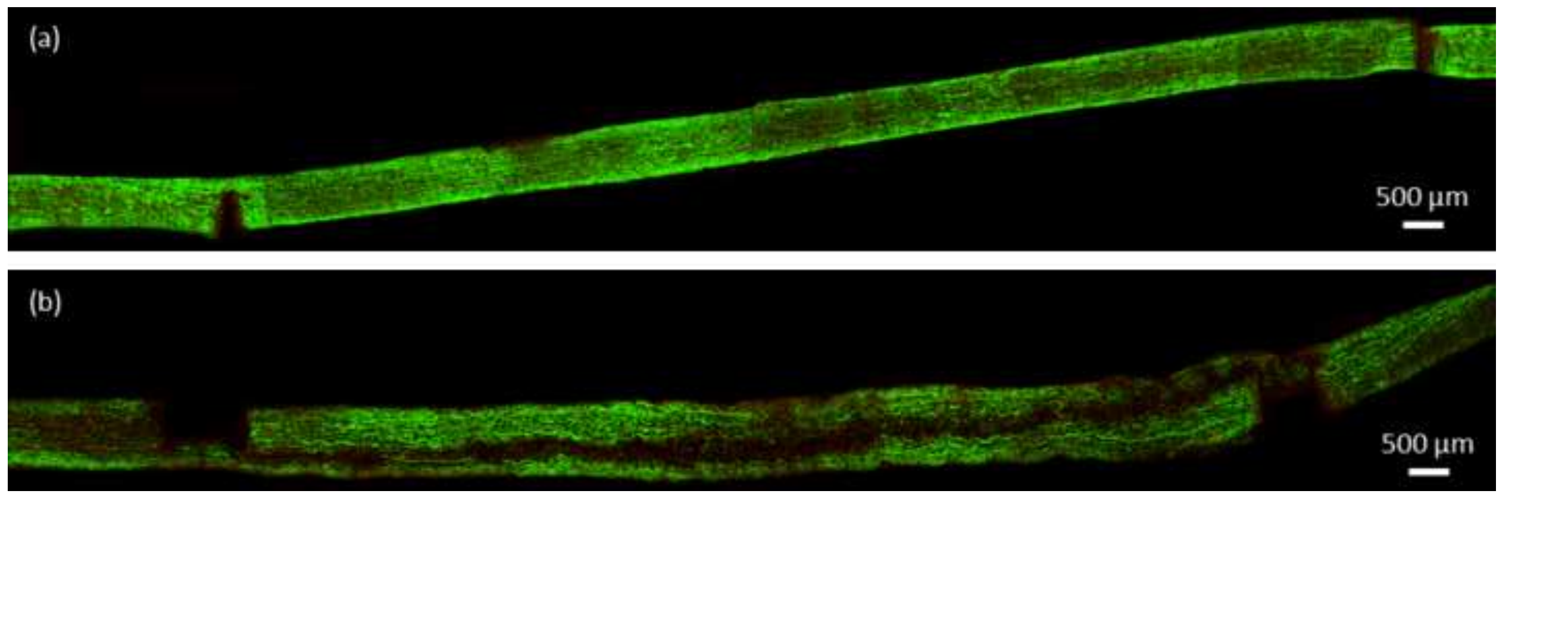

.

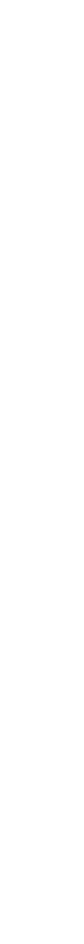

. 


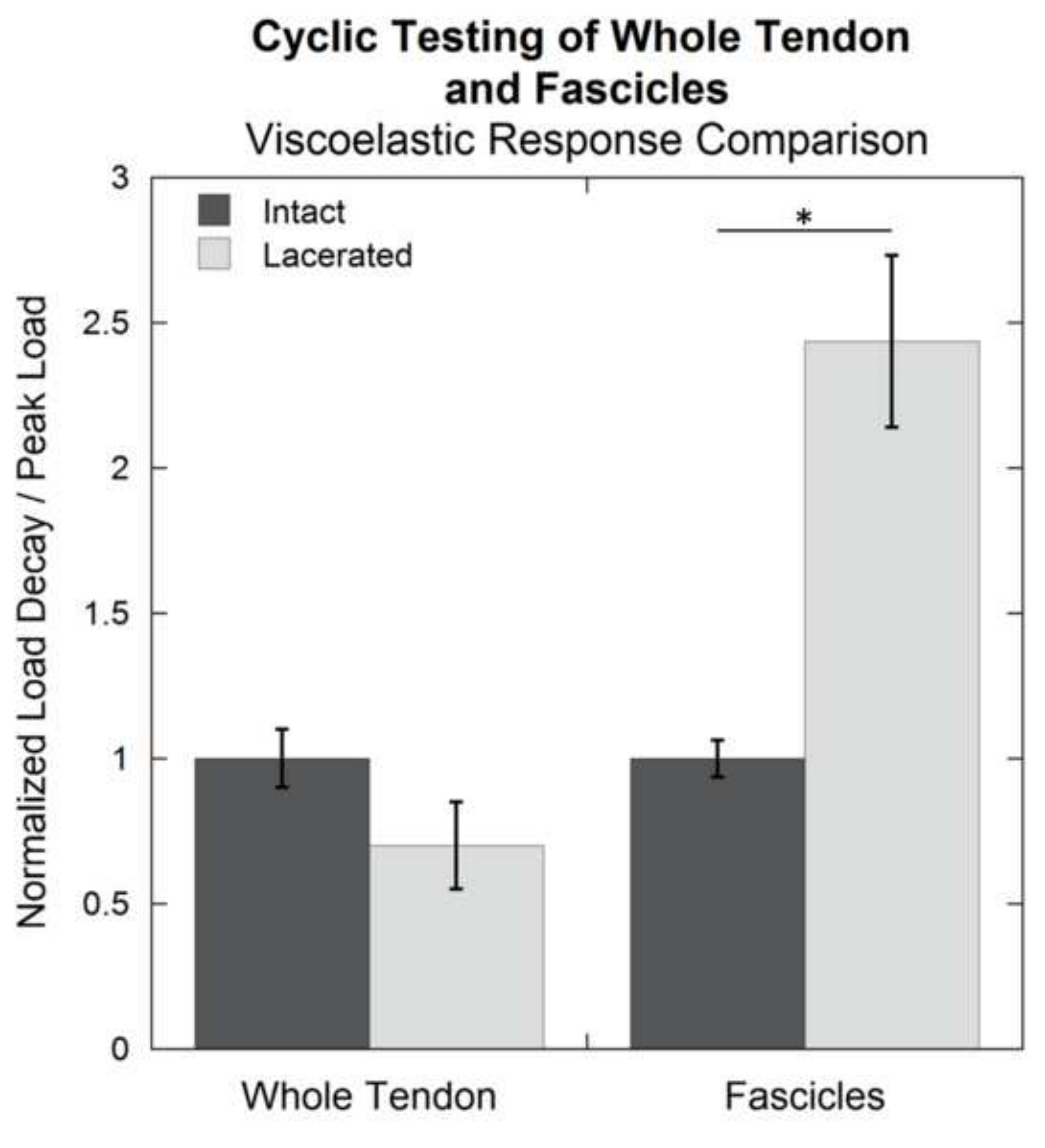

Cyclic Testing of Whole Tendon

\section{Viscoelastic Response}


Tables

Table 1

\begin{tabular}{c|l|}
\cline { 2 - 2 } & \multicolumn{1}{|c|}{ Experimental Sub-Groups } \\
\hline \multirow{2}{*}{ Pair 1 } & Double Laceration +Mechanical Testing \\
\cline { 2 - 2 } & Double Laceration \\
\hline \multirow{2}{*}{ Pair 2 } & Single Laceration + Mechanical Testing \\
\cline { 2 - 2 } & Single Laceration \\
\hline \multirow{2}{*}{ Pair 3 } & Intact + Mechanical Testing \\
\cline { 2 - 2 } & Intact \\
\hline
\end{tabular}

